\title{
Research on China's rural household energy consumption - Household investigation of typical counties in 8 economic zones
}

\author{
Wang Xiaohua $^{\mathrm{a}, \mathrm{b}, *}$, Li Kunquan ${ }^{\mathrm{a}, \mathrm{b}}$, Li Hua ${ }^{\mathrm{a}, \mathrm{b}}$, Bai Di $^{\mathrm{a}, \mathrm{b}}$, Liu Jingru ${ }^{\mathrm{c}}$ \\ a College of Engineering, Nanjing Agricultural University, Nanjing 210031, China \\ b Engineering Laboratory of Modern Facility Agricultural Technology and Equipment, Jiangsu Province, Nanjing 210031, China \\ ${ }^{\mathrm{c}}$ State Key Laboratory of Urban and Regional Ecology, Research Center for Eco-Environmental Sciences, Chinese Academy of Sciences, Beijing 100085, \\ China
}

\section{A R T I C L E I N F O}

\section{Keywords:}

Biomass energy

Household energy consumption

Rural energy

Household investigation

China

\begin{abstract}
A B S T R A C T
Rural household energy consumption is an important component of national energy consumption and plays an important role in rural social and ecological environment developments. In this paper, energy consumption of 1440 households in 8 typical counties of 8 China's economic zones was investigated. The investigation data analysis revealed significant difference of different economic zones in rural household energy consumption level and structure. For 8 studying counties, the annual average energy consumption per capita was 26.7 GJ, 10.4 GJ the lowest (Shanghang County) and 86.6 GJ the highest (Shulan County). In energy consumption, straw, biogas, fuel wood and electricity accounted for 44.33\%, 23.13\%, 12.79\% and 9.61\%, respectively. Rural families with high incomes preferred commercial energies (e.g. electricity and liquefied petroleum gas (LPG)) to biomass energy (e.g. straw and fuel wood). The traditional biomass energy is still the main energy source for China's rural household. Research results provide references to understand current situations and future development of China's rural household energy consumption, and formulate related energy and environmental policies.
\end{abstract}

\section{Introduction}

With the rapid growth of energy demand and consumption, problems concerning energy, environment and climate changes become increasingly prominent. Countries in the world are look for a way of harmonious development of society, economy, resources and environment [1-3]. Energy conservation, energy efficiency and renewable energy utilization could reduce fossil energy consumption effectively. This is good for ecological and environmental protection, mitigation of global warming and collaborative promotion of sustainable social development [4-7].

Energy supply-demand balance in rural areas of developing countries is closely related with local economic and social development as well as ecological environmental protection. This energy supplydemand balance in developing countries is an important content of sustainable development strategy of energy sources in the world [811]. Rural household energy consumption mainly refers to energies used for daily life of rural household, including illumination, cooking, heating, hot water and household appliances [12-14]. In rural areas of China, a developing countries, basic energy demands for daily life are satisfied by biomass energies (straw and fuel wood) [15-18]. Domestic researches on energy problems in rural areas began from the 20th century and have achieved abundant fruits [19-21]. Zhou et al. thoroughly analyze household energy consumption in terms of energy sources and energy end-uses in villages of Huantai County [22]. Zhang and Guo identified the contributing role of different factors affecting the change of rural residential energy consumption in China [23]. The development potential of biomass and other renewable resources has also been studied by Li et al. [24]. However, most of existing researches on rural household energy consumption are macroscopic one and lack of the first-hand survey data as well as related information, resulting in the unsatisfying data reliability, comprehensiveness and accuracy. Most of them focus on some local areas, such as eastern China, western China and northern China. Existing researches are incomparable because they are carried out by different experts in different periods. Therefore, it is difficult to comprehend overall situation of the national rural household energy consumption [25-27]. Due to China's extensive territory, there's great difference among regions with respect to society, nature, economic-ecological environment and lifestyle. Since rural household energy consumption in China depends highly on noncommercial energy sources and available natural resources, there's outstanding regional difference in changes of rural household energy consumption.

This paper chose typical regions of different types for investigation

\footnotetext{
* Corresponding author at: College of Engineering, Nanjing Agricultural University, Nanjing 210031, China.

E-mail address: xhwang@njau.edu.cn (W. Xiaohua).
} 
of rural household energy consumption. Current situation of rural household energy consumption and regional difference were comprehended. It provides references to study level, substitution, variation, influencing factors and development law of household energy consumption.

\section{Method and data}

According to regional differences in nature, climate, economic development level and industrial status, China has been divided into 8 economic zones including south coastal regions, east coastal regions, north coastal regions, northeast China, midstream region of the Yangtze River, midstream region of the Yellow River, southwest China, northwest region. One typical county of 8 China's economic zones were chosen as the research objects. Typical county systems were determined by comprehensive analysis on district, environment, resources, economic level, industrial structure and rural household energy consumption. These 8 counties are Jing County (Hebei province), Jinhu (Jiangsu province), Shanghang (Fujian province), Shulan (Jilin province), Xinmi (Henan province), Yunmeng (Hubei province), Weiyuan (Gansu province) and Tongnan (Chongqing province). In each county, 180 rural families (2 towns, 3 villages of each town and 30 families of each village) were chosen randomly, getting 1440 effective samples. 54 college students and graduate students were invited as the investigator and trained together. The household investigation was implemented using uniform printed questionnaire. Questionnaire could be filled by others and main survey contents include basic family status, biomass harvest yield, energy consumption, attitude toward utilization of different energy sources, etc.

\section{Results and analysis}

\subsection{Nature and basic conditions of investigated rural household in typical counties}

These 8 counties are plains, mountainous regions and plateaus. Shulan and Weiyuan are in north China and have low annual average temperature, but rest regions show similar annual average temperature. According to survey data statistics, Shanghang County has the highest household permanent residences (5.08) and Tongnan has the lowest (2.75). There's prominent difference in annual household income per capita. Jinhu has the highest annual household income per capita (6372.6 RMB) and the Tongnan has the lowest (848.8 RMB). Jinhu shows the highest agricultural acreage per capita $\left(2980 \mathrm{~m}^{2}\right)$ and Xinmi shows the lowest $\left(327 \mathrm{~m}^{2}\right)$ (Table 1).

\subsection{Household energy consumption level and structure}

The survey data analysis reveals significant regional difference in rural household energy consumption (Table 2). The lowest $(10,435.2 \mathrm{MJ})$ and the highest (86,568.8 MJ) annual household energy consumption per capita were in Shanghang and Shulan. The average value of 8 studying counties was 26,725.2 MJ. Average proportions of straw, biogas, fuel wood and electricity in household energy consumption of a county were $44.33 \%, 23.13 \%, 12.79 \%$ and $9.61 \%$, respectively. Northern China (Shulan, Weiyuan and Jing County) where has heating demands in winter show higher rural household energy consumption than rest economic zones. Electricity is universal in rural areas, but there's still regional difference of electricity consumption. Compared to poor counties, Jing County, Jinhu, Shanghang and Yunmeng in developed economic zones consume more electricity and commercial energy sources. This is related with higher household income per capita of these regions. Proportion of coal consumption in Jing County, Xinmi and Weiyuan where are rich of coal resources is higher than that of other regions. Rural families with high incomes prefer commercial energy sources (e.g. electricity and liquefied gas) to traditional fuels (biomass). This is one of basic features of well-off household energy consumption in China. Nevertheless, survey data reflects that commercial energy has not replaced the traditional energy sources completely in rural household energy consumption of China and traditional biomass energy is still an important part of household fuel structure.

To study basic features of rural household energy consumption, effective heat per capita, proportion of commercial energy in effective heat and electricity consumption per capita of 8 studying counties were calculated (Fig. 1). Household effective heat per capita is the total annual per-capita effective heats for cooking gained from various energies (thermal conversion efficiency of straw and fuel wood is $18 \%$, and thermal conversion efficiencies of coal as well as liquefied gas and biogas are $22 \%$ and 60\%) [16]. It is an index of effective household energy demand and reflects actual consumption level of effective heats, including household cooking, hot water, swine breeding, etc. To avoid influences of regional climatic variations, it excludes demands of winter heating and air condition effective heats (electricity consumed by air condition is counted in per capita electricity consumption index and electrical energy is calculated according to equivalent values: $1 \mathrm{kWh}=11,840 \mathrm{~J}$ ). According to the statistics, per capita effective heat mostly concentrates between 2.7 and 2.9 GJ, averaging at 2.86 GJ. This reflects household energy consumption situation under current rural social and economic development levels in China.

Proportion of commercial energy in effective heat is a qualitative index of energy consumption, which is $33.62 \%$ in average of 8 studying counties. Generally speaking, commercial energy only contributes $1 / 3$ of effective heats, which is far lower than the commercialization level (commercial energy accounts for more than $50 \%$ of the effective heats) of rural household energy consumption. The big regional difference demonstrates diversity and complexity of household energy consumption for cooking. In Xinmi County, proportion of commercial energy in per capita effective heats reaches $65.40 \%$, which is caused by low availability of straw and fuel wood given the small per capita agricultural acreage $\left(327 \mathrm{~m}^{2}\right)$. Residents in Xinmi County are used to consume coals for daily energy demands. Yunmeng County has high rural income per capita (about $5700 \mathrm{RMB}$ ). Local commercial energy sources mainly liquefied gas and coals, resulting in the high proportion of commercial energy in per capita effective heats. The proportion of

Table 1

Basic family situation on typical counties.

\begin{tabular}{|c|c|c|c|c|c|c|}
\hline & Physiognomy & $\begin{array}{l}\text { Annual average } \\
\text { temperature } /{ }^{\circ} \mathrm{C}\end{array}$ & $\begin{array}{l}\text { Household permanent } \\
\text { residences }\end{array}$ & $\begin{array}{l}\text { Labor force per } \\
\text { household }\end{array}$ & $\begin{array}{l}\text { Annual household income per } \\
\text { capita / RMB }\end{array}$ & $\begin{array}{l}\text { Agricultural acreage per } \\
\text { capita } / \mathrm{m}^{2}\end{array}$ \\
\hline Jingxian & Plain & 12.5 & 3.79 & 2.23 & 4168.7 & 2560 \\
\hline Jinhu & Plain & 14.6 & 3.12 & 1.87 & 6372.6 & 2980 \\
\hline Shanghang & Mountainous region & 19.8 & 5.08 & 2.62 & 3499.9 & 393 \\
\hline Shulan & Plain & 3.9 & 3.91 & 2.37 & 3941.1 & 2400 \\
\hline Xinmi & Mountainous region & 14.3 & 4.38 & 2.00 & 2908.9 & 327 \\
\hline Yunmeng & Plain & 16.0 & 3.90 & 2.69 & 5714.8 & 1013 \\
\hline Weiyuan & Plateau & 6.0 & 3.89 & 1.94 & 908.8 & 1673 \\
\hline Tongnan & Mountainous region & 17.9 & 2.75 & 1.53 & 848.8 & 693 \\
\hline
\end{tabular}


Table 2

Per capita rural household energy consumption on typical counties.

\begin{tabular}{|c|c|c|c|c|c|c|c|c|}
\hline & & Electricity & Firewood & Straw & Coal & Liquefied Petroleum Gas & Biogas & Total \\
\hline \multirow[t]{2}{*}{ Jingxian } & Energy Consumption/MJ & 2776.0 & 2.3 & 13074.6 & 5743.3 & 699.3 & - & 22295.5 \\
\hline & Percent of Energy Consumption/\% & 12.45 & - & 58.65 & 25.76 & 3.14 & - & 100 \\
\hline \multirow[t]{2}{*}{ Jinhu } & Energy Consumption/MJ & 4158.5 & 6832.5 & 4254.3 & 1.8 & 807.8 & 532.6 & 16587.4 \\
\hline & Percent of Energy Consumption/\% & 25.07 & 41.19 & 25.65 & 0.01 & 4.87 & 3.21 & 100 \\
\hline \multirow[t]{2}{*}{ Shanghang } & Energy Consumption/MJ & 3077.6 & 4263.7 & 26.1 & - & 897.8 & 2167.5 & 10435.2 \\
\hline & Percent of Energy Consumption/\% & 29.49 & 40.86 & 0.28 & - & 8.60 & 20.77 & 100 \\
\hline \multirow[t]{2}{*}{ Shulan } & Energy Consumption/MJ & 2272.4 & 2472.6 & 62504.1 & 1611.5 & 129.3 & 17579.0 & 86568.8 \\
\hline & Percent of Energy Consumption/\% & 2.62 & 2.86 & 72.20 & 1.86 & 0.15 & 20.31 & 100 \\
\hline \multirow[t]{2}{*}{ Xinmi } & Energy Consumption/MJ & 2562.0 & 80.3 & 17.3 & 3296.8 & 847.9 & 5477.5 & 12281.8 \\
\hline & Percent of Energy Consumption/\% & 20.86 & 0.65 & 0.14 & 26.84 & 6.91 & 44.60 & 100 \\
\hline \multirow[t]{2}{*}{ Yunmeng } & Energy Consumption/MJ & 2591.6 & 2305.5 & 3574.4 & 1164.2 & 841.8 & 148.6 & 10626.0 \\
\hline & Percent of Energy Consumption/\% & 24.39 & 21.70 & 33.63 & 10.96 & 7.92 & 1.40 & 100 \\
\hline \multirow[t]{2}{*}{ Weiyuan } & Energy Consumption/MJ & 1170.3 & 2199.4 & 6361.4 & 5005.3 & 36.3 & 23267.2 & 38040.0 \\
\hline & Percent of Energy Consumption/\% & 3.08 & 5.78 & 16.72 & 13.16 & 0.10 & 61.16 & 100 \\
\hline \multirow[t]{2}{*}{ Tongnan } & Energy Consumption/MJ & 1926.3 & 9185.2 & 4955.1 & 7.6 & 622.5 & 270.2 & 16967.0 \\
\hline & Percent of Energy Consumption/\% & 11.35 & 54.14 & 29.20 & 0.04 & 3.67 & 1.60 & 100 \\
\hline \multirow[t]{2}{*}{ Average } & Energy Consumption/MJ & 2567.0 & 3417.8 & 11846.2 & 2103.9 & 610.2 & 6180.3 & 26725.2 \\
\hline & Percent of Energy Consumption/\% & 9.61 & 12.79 & 44.33 & 7.87 & 2.28 & 23.13 & 100 \\
\hline
\end{tabular}

commercial energy in per capita effective heats in Shulan County is relatively lower, which is related with local rich straw resources.

Household electricity consumption is mainly for civilized life, including TV, washing machine, electric fan, and so on. The per capita electricity consumption is an important index of living standard and living quality. The data statistics show that the household electricity consumption of 8 counties ranges between 100 and $250 \mathrm{kWh}$ per capita per year, presenting outstanding differences.

Variety of energies consumed by China's rural families is mainly determined by availability of local resources. In Jing County, coal and straw are main residential energy resources, accounting for $84 \%$ of total rural household energy consumption. Fuel wood is the main residential energy resources in Jinhu and takes up $41.19 \%$ of the total rural household energy consumption, while straw and electricity occupy about $25 \%$. Shanghang County mainly consumes fuel wood, supplemented by electricity and biogas. Straw and biogas are dominant energy consumptions in Shulan County and the proportion of straw consumption reaches as high as $72 \%$. In Xinmi County, biogas and coal account for about $44 \%$ and $26 \%$ in the energy consumption structure. Straw and fuel wood are main energy consumption patterns in Yunmeng County, supplemented by electricity. Proportions of straw, fuel and electricity are similar, but proportion of straw is slightly higher, about $33 \%$. In Weiyuan County, biogas and straw are main energy sources, followed by coals. Energy consumption structure in Tongnan County focuses on traditional biomass energies (e.g. fuel wood and straw). Proportion of fuel wood in total rural household energy consumption is $54 \%$.

To sum up, regional differences in China's rural household energy consumption level and structure are mainly influenced by local social and economic development level, availability of energy sources, climate, lifestyle, etc.

\subsection{Comparison analysis on household biomass energy consumption}

\subsubsection{Fuel wood}

Fuel wood plays an important role in China's rural life. It is an important energy source of household cooking and heating in rural areas. With economic development, income growth and circulation channel perfection in rural areas, the proportion of fuel wood in total rural energy consumption declines gradually. In 8 studying counties, per capita fuel wood consumption in Tongnan reaches as high as 9185.2 MJ. There are rich fuel wood resources and peasant household are used to use it as fuels. Per capita fuel wood consumption in Jinhu is relatively high $(6832.5 \mathrm{MJ})$. This is mainly caused by rich forest resources, abundant wood processing plants and high availability of fuel woods.

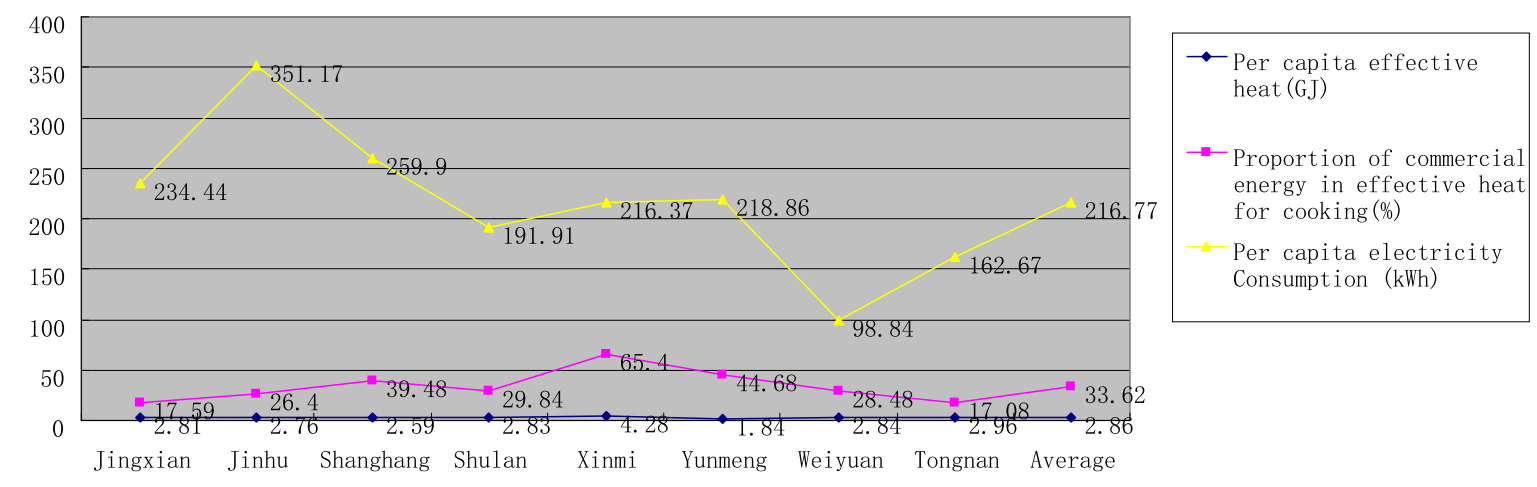

Fig. 1. Characteristic indexes of rural household energy consumption on eight counties. 


\subsubsection{Straw}

Straw consumption pattern in China is in accordance with crop distribution. Viewed from the gross distribution, crop straw resources mainly concentrate in main rural areas in central and northeast China as well as some provinces in southwest China. Heilongjiang, Hebei, Shandong, Jiangsu and Sichuan possess the highest crop straw resources, accounting for about over $36 \%$. Shulan is in the intersection of Zhuangguangcai Mountain of Changbai Mountains and the Laoyeling Mountain and transits to the Songnen Plain. It possesses fertile lands, rich water conservancy resources and good climate, which are very good for agricultural development. Shulan is one regions of rice production in Jilin Province. With rich rice, corn and bean, it is an important commodity grain base in China and thereby possesses tremendous straw resources. Due to the low annual average temperature $\left(3.9^{\circ} \mathrm{C}\right)$, peasant households in Shulan mainly use straw for heating. Similarly, per capita straw consumption in Jing County is very high. As the national commodity grain base and excellent cotton base, Jing County has good agricultural development conditions and mainly plants corns, wheat and cotton. However, the proportion of straw in rural household energy consumption is only $0.14 \%$ and $0.28 \%$ in Xinmi and Shanghang, respectively.

\subsubsection{Biogas}

China has been attaching high attention to the development of renewable energy sources (e.g. biogas) in rural areas and governments at all levels offer great supports to construction of rural biogas infrastructure, achieving leap growth of biogas consumption in rural areas. Among 8 studying counties, Jinhu is the national rural energy comprehensive construction county of "the 9th Five-year Plan" in Jiangsu Province. Rural household biogas construction has become an important component of new rural construction. Shulan is the pilot biogas construction county determined by the Ministry of Agriculture, where the biogas utilization reaches $97 \%$ and the per capita biogas consumption is very high. Weiyuan County has been promoting the new autocycle high-efficiency biogas tank since 2005, which solves the long-term difficult biogas discharge problem. Combining with ecological energy source patterns, it overcomes limitation of zero biogas production in winter in cold regions and gives full play of biogas. Shanghang started to build biogas tank and promoted energy-efficient equipments (e.g. solar water heater ad fuel-saving stove) in 1997. Xinmi County achieved good biogas development through multiple financing channels of "government subsidy, peasant collection and social aid". Per capita biogas consumption in Shulan and Weiyuan is very high, while that of other regions is very low, showing great regional distance. Per capita biogas consumption in Jing County is almost zero. This is because local peasant households prefer fuel wood and coals. Biogas tank construction started late in Jing County and hasn't been populated yet.

\section{Conclusions}

This paper studies rural household energy consumption level and structure in 8 studying counties as well as corresponding influencing factors. It mainly concludes that:

(1) Generally, traditional biomass energy is the main component in rural household energy consumption in China at present. It still needs some time to popularize commodity energy consumption in rural household energy consumption. With the economic and social development in rural areas, commercialization of rural household energy consumption in China is accelerating. With the increasing household income level in rural areas, proportions of traditional biomass energy (e.g. straw and fuel wood) in household energy consumption is decreasing gradually. It has to take some time to replace biomass energy with commercial energy sources completely.
(2) Electricity has become a necessary energy source of rural families. With the increase of rural household income, proportions of commercial energy sources like electricity and LPG increase quickly. Commercialization of China's rural household energy consumption is accelerating with the rural economic and social development.

(3) In rural household energy consumption, combination of traditional biomass energies and commercial energy sources is universal.

(4) There's evident regional difference in energy consumption structure. Generally, east China has the highest energy consumption level, followed by central China and west China successively. Geographical difference is the main cause of different rural household energy consumption level between south China and north China. North China where is very cold in winter and needs heating requires extra energy sources, thus resulting in the far higher total rural household energy consumption compared to that of south China.

(5) This paper further discloses the regional difference in rural household energy consumption level and structure. Based on the comparative analysis, it finds that rural household energy consumption is mainly influenced by local social and economic development level, local energy availability, climate, lifestyle, etc.

\section{Discussion and policy suggestions}

Some economical developed rural regions in China (e.g. south region of Jiangsu) have basically entered into commercialization stage of household energy consumption. Rural biomass which have been used as household energy sources for a long time are replaced gradually, so the large quantity of straw sources will bring new environmental problems to rural areas. Some policy suggestions are put forward:

(1) With full understanding on regional difference of rural energy consumption and considering actual situations of different regions, related policies shall be formulated to increase household energy consumption level in rural areas, optimize and update energy consumption structures, and guide peasant households to use energies reasonable.

(2) Increase R \& D efforts on traditional biomass energies and change them into energies as efficient, clean and convenient as commodity energies.

(3) Establish a demonstration base of biomass energy development and utilization. Organize industrial demonstration of biomass energy utilization and accelerate transformation and application of suitable technologies.

(4) The related governmental departments shall take the initiative to promote biomass energy utilization project, optimize regional layout by considering local actual situations, and facilitate achievement transformation in biomass power boiler, breaking plant and solidifying and moulding devices.

(5) With existing supportive policies, government shall encourage enterprises to make large-scale and deep utilization of biomass energy sources and highlight supports and guidance to collection service systems. Position and role of reasonable development and utilization of biomass energy sources in the energy sustainable development shall be propagandized greatly in rural areas with rich biomass energy sources in order to make the public be aware of the importance and necessity of development and utilization of biomass energy sources.

(6) Develop local energy sources and perfect the energy service system. In regions with rich renewable energy sources, it shall persist in the principle of adjust measures to local conditions and make full use of various renewable energy sources, such as solar energy and wind energy. This can meet rural energy demands well and can protect ecological environment. 
(7) Give full attentions to rural household demands for commodity energy sources and enlist it into China's energy supply system for overall planning. During rural economic development in China, rural household energy consumption depends more and more on commodity energy sources. With the income increase of peasants, their demands for commodity energy sources will increase. Government and involved departments shall consider the necessity of this process thoroughly, pay high attentions to rural household demands for commodity energies, and enlist it into China's energy supply system for overall planning.

(8) Enhance propagation in rural areas with rich biomass energy sources on the role of reasonable development and utilization of biomass energies in sustainable development and environmental protection, so that the public can realize importance and necessity of biomass energy development and utilization.

China covers an extensive territory and rural household energy consumption is influenced by various factors. Although this paper discloses regional difference in rural household energy consumption level and structure to a certain extent, it only investigates situations of a fixed time point and only chooses one typical county to represent each type of economic zone. Therefore, further tracking study on rural household energy consumption is needed. If there are sufficient capital and investigators, further study shall increase quantity of typical counties to comprehend the general variation law of rural household energy consumption in China.

\section{Acknowledgments}

This work was supported by the National Natural Science Foundation of China (No. 71173209). We would like to thank the investigators participated in this project and the anonymous referees for their helpful suggestions and corrections on the earlier draft of our paper and upon which we have improved the content.

\section{References}

[1] Yuan Y, Zhao JA. Study on the supply capacity of crop residue as energy in rural areas of Heilongjiang province of China. Renew Sustain Energy Rev 2014;38:526-36.

[2] Guta DD. Effect of fuelwood scarcity and socio-economic factors on household biobased energy use and energy substitution in rural Ethiopia. Energy Policy 2014;75:217-27.

[3] Tang X, Liao H. Energy poverty and solid fuels use in rural China: analysis based on national population census. Energy Sustain Dev 2014;23:122-9.

[4] Zhou ZR, Wang XH, Chen Q, et al. Evolvement of well-off rural household energy consumption structure in northern China: a case study in Huantai county of Shangdong Province. Trans Chin Soc Agric Eng (Trans CSAE) 2007;23(3):192-7, [in Chinese with English abstract].

[5] Guo XD, Niu SW, Li GZ, et al. Estimate on the eco-economic benefits of rural energy sources construction and de-farming and reforestation. China Popul Resour Environ 2006;16(3):98-102, [in Chinese with English abstract].
[6] Mazzola S, Astolfi M, Macchi E. The potential role of solid biomass for rural electrification: a techno economic analysis for a hybrid microgrid in India. Appl Energy 2016;169:370-83.

[7] Debnath KB, Mourshed M, Chew SPK. Modelling and forecasting energy demand in rural households of Bangladesh. Energy Procedia 2015;75:2731-7.

[8] Wang XH. Situation and development of rural household energy consumption in China. J Nanjing Agric Univ 2004;17(3):134-41, [in Chinese with English abstract].

[9] Yan LZ, Min QW, Cheng SK. Energy consumption and bio-energy development in rural areas of China. Resour Sci 2005;27(1):8-13, [in Chinese with English abstract].

[10] Li X, Lin C, Wang Y, Zhao LY, et al. Analysis of rural household energy consumption and renewable energy systems in Zhangziying town of Beijing. Ecol Model 2015;318:184-93.

[11] Wang XH, Feng ZM. Study on rural household energy consumption in China: consumption level and affecting factors. Trans Chin Soc Agric Eng (Trans CSAE) 2001;17(5):88-91, [in Chinese with English abstract].

[12] Sameer P, Anish K, Anna L, et al. A model for cost-benefit analysis of cooking fuel alternatives from a rural Indian household perspective. Renew Sustain Energy Rev 2016;56:291-302.

[13] Niu SW, Zhang X, Zhao CS, et al. Household energy use and emission reduction effects of energy conversion in Lanzhou city, China. Renew Energy 2011;36(5):1431-6.

[14] Shonali P, Jiang LW. The household energy transition in India and China. Energy Policy 2008;36(11):4022-35.

[15] Zhou Y, Liu YS, Wu WX, Li YR. Effects of rural-urban development transformation on energy consumption and $\mathrm{CO}_{2}$ emissions: a regional analysis in China. Renew Sustain Energy Rev 2015;52:863-75.

[16] Wang XJ, Lu XA, Yang GH, et al. Development process and probable future transformations of rural biogas in China. Renew Sustain Energy Rev 2016;55:703-12.

[17] Zhang M, Song Y, Li P, et al. Study on affecting factors of residential energy consumption in urban and rural Jiangsu. Renew Sustain Energy Rev 2016;53:330-7.

[18] Li P, Wang XH. Evaluation on benefit of rural household biogas based on environmental cost. China Biogas 2007;25(2):31-3, [in Chinese with English abstract]

[19] Li LL, Wang YX, Wang XH. On the establishment, operation mechanism and development strategy of rural biogas association: the case in Xiaoliji village, Jiangsu province. China Biogas 2009;27(5):33-6, [in Chinese with English abstract].

[20] Wang F, Li X, Chen JF, et al. Optimal spatial decision of cropland bio-energy intensive application. Trans Chin Soc Agric Eng (Trans CSAE) 2009;25(9):232-6, [in Chinese with English abstract].

[21] Wang JC, Dai L, Tian YS, et al. Analysis of the development status and trends of biomass energy industry in China. Trans Chin Soc Agric Eng (Trans CSAE) 2007;23(9):276-82, [in Chinese with English abstract].

[22] Zhou ZR, Wu WL, Wang XH, Chen Q, Wang Q. Analysis of changes in the structure of rural household energy consumption in northern China: a case study. Renew Sustain Energy Rev 2009;13:187-93.

[23] Zhang M, Guo FY. Analysis of rural residential commercial energy consumption in China. Energy 2013;52:222-9.

[24] Li JF, Hu RQ, Song YQ, Shi JL, Bhattacharya SC, Salam AP. Assessment of sustainable energy potential of non-plantation biomass resources in China. Biomass Bioenergy 2005;29:167-77.

[25] Zhou ZG, Wu WL. Status quo and prospects of biomass energy. Trans Chin Soc Agric Eng (Trans CSAE) 2005;21(12):12-5, [in Chinese with English abstract].

[26] Fang F, Wang F, Wang H. Current status and application prospects of biomass energy. Trans Chin Soc Agric Eng (Trans CSAE) 2003;19(7):133-5, [in Chinese with English abstract].

[27] Li GZ, Niu SW, Yang Z, et al. The analysis on environmental and economic cost of rural household energy consumption in loess hilly region of Gansu Province. J Nat Resour 2008;23(1):15-24, [in Chinese with English abstract]. 